Int. J. Dev. Biol. 50: 505-510 (2006)

doi: $10.1387 / \mathrm{ijdb} .052116 \mathrm{mz}$

Developmental Expression Pattern

\title{
Tbx1 is expressed at multiple sites of epithelial-mesenchymal interaction during early development of the facial complex
}

\author{
MARIA ZOUPA ${ }^{1}$, MAISA SEPPALA ${ }^{1}$, THIMIOS MITSIADIS ${ }^{1}$ and MARTYN T. COBOURNE*,2 \\ ${ }^{1}$ Department of Craniofacial Development and ${ }^{2}$ Department of Orthodontics and Craniofacial Development, King's College London, \\ GKT Dental Institute, Guy's Hospital, London, UK
}

\begin{abstract}
TBX1 encodes a T-box-containing transcription factor, which is thought to be a key player in the aetiology of the DiGeorge and Velocardiofacial syndromes (DGS/VCFS). In addition to defects affecting structures derived from the pharyngeal pouches, these patients exhibit varying degrees of facial dysmorphology and cleft palate. We have analysed the expression of murine Tbx1 during early facial development and found transcripts at sites of known epithelialmesenchymal interaction. In particular, $T b x 1$ was expressed in epithelium of the early facial processes, including the fronto-nasal, medial and lateral nasal and palatine. Transcripts were also localised to the epithelium of developing tooth germs and hair follicles at several stages during their early development. Together, these expression domains suggest a role for $T b x \mathbf{1}$ in mediating epithelial-mesenchymal signalling in regions of the developing face, a finding which is consistent with the spectrum of facial deformity encountered amongst subjects affected by DGS/VCFS.
\end{abstract}

KEY WORDS: Tbx1, facial development, tooth morphogenesis, hair follicle morphogenesis

The vertebrate face arises from the interaction of several embryonic cell lineages; ectoderm, endoderm, mesoderm and cranial neural crest. These cell populations construct the face via coordinated growth and differentiation, in the form of a series of simple swellings. Principal amongst these, are the maxillary and mandibular processes of the first pharyngeal arch and the frontonasal process. The complex molecular mechanisms underlying development of these processes are mediated by an array of signalling molecules and transcription factors, generating interaction between the epithelium and underlying mesenchyme (FrancisWest et al., 2003). Any perturbation of these mechanisms can lead to developmental anomalies of the craniofacial region, which can include varying degrees of facial dysmorphology and orofacial clefting.

T-box genes encode a large group of transcription factors characterized by a 180-amino-acid DNA-binding domain homologous to the murine Brachyury (T) gene product (Herrmann et al., 1990). TBX1 encodes one member of the vertebrate family of Tbox-containing transcription factors and is thought to be a key player in the aetiology of the DiGeorge and Velocardiofacial syndromes (DGS/VCFS) (Jerome and Papaioannou, 2001, Lindsay et al., 2001, Merscher et al., 2001, Yagi et al., 2003). These syndromes form part of a group of related human dysmorphic disorders that result from deletion or rearrangement of a $3 \mathrm{Mb}$ region of chromosome 22q11 (Baldini, 2002, Baldini, 2005,
Scambler, 2000). DGS/VCFS subjects are characterised by defects in the cardiac outflow tract and aortic arch, thymic and parathyroid aplasia or hypoplasia, learning and/or behavioural difficulties and anomalies of the craniofacial region (Klewer et al., 2004). The principle clinical phenotypes present within these syndromes are thought to result from an absence of normal pharyngeal pouch signalling and localised disruption of neural crest migration within the pharyngeal arch system (Kochilas etal., 2002, Vitelli et al., 2002a). The candidacy of TBX1for DGS/VCFS has been based upon its chromosomal location (Chieffo et al., 1997), expression domain in the endoderm and mesodermal core of the developing pharyngeal arches (Chapman et al., 1996, Kochilas etal., 2003, Sauka-Spengler et al., 2002) and the finding that mice generated with a targeted deletion in murine Tbx 1 (Jerome and Papaioannou, 2001, Lindsay et al., 2001, Merscher et al., 2001) or hemizygous deletion of chromosome 16 (Lindsay et al., 2001, Merscher et al., 2001) exhibit a spectrum of phenotypic effects encompassing most of the common DGS/VCFS malformations. More recently, mutation in TBX1 has been identified in one case of sporadic DGS (Yagi et al., 2003).

The craniofacial malformations in DGS subjects include micrognathia, ear abnormalities, blunted nose, hypertelorism and cleft

Abbreviations used in this paper: DGS, DiGeorge syndrome; Tbx, T-box; VFCS, Velocardiofacial syndrome. 

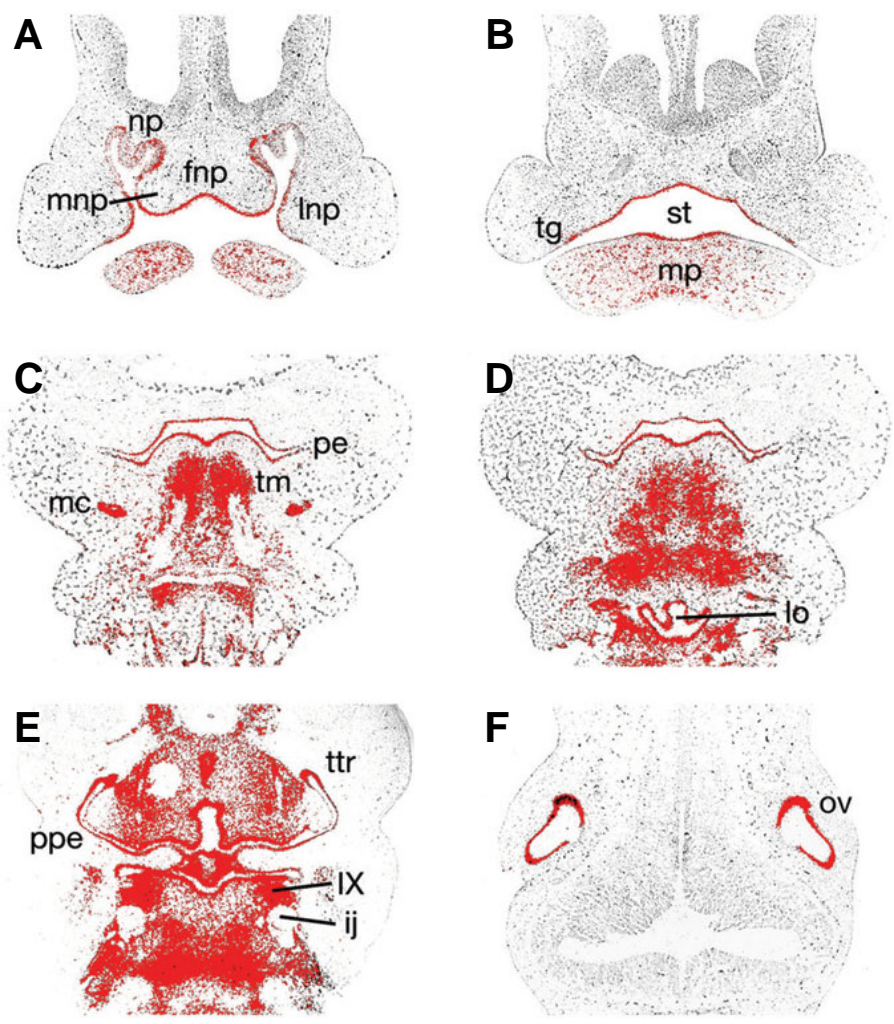

Fig. 1. Tbx 1 expression in the craniofacial region of the developing mouse embryo at E11.5 (A-F). Tbx1 is expressed in the epithelium of the developing facial processes and early oral cavity (A,B), whilst more proximally, transcripts are localised in the endoderm and mesoderm of the pharyngeal region (C-E). In the otic vesicle, expression is intense within the lateral ectoderm (F). fnp, fronto-nasal process; ij, internal jugular vein; Inp, lateral nasal process; lo, laryngeal orifice; mc, Meckel's cartilage; mnp, medial nasal process; mp, mandibular process; $n p$, nasal pit; ov, otic vesicle; pe, pharyngeal endoderm; ppe, pharyngeal pouch endoderm; st, stomatodeum; tg, tooth germ; tm, tongue mesoderm; ttr, tubotympanic recess; $I X$, inferior ganglion of glossopharyngeal nerve. palate; whilst VCFS involves a more severe facial dysmorphogenesis (pear-shaped nose, long face, malar flattening and micrognathia) in addition to cleft palate (Klewer et al., 2004) and hypodontia (Oberoi and Vargervik, 2005). We present a detailed analysis of $T b \times 1$ expression in the developing facial region of mice and report the presence of transcripts in epithelial tissues that play a crucial role in normal development of the face and its appendages. Tbx 1 expression is restricted to epithelial regions of the developing facial processes, palatal shelves, tooth germs and epidermal invaginations of developing hair follicles. Together, these expression domains are consistent with the phenotypic consequences of a loss of TBX1 function in human subjects and suggest the possibility of an important additional role for this transcription factor during development of regions beyond the pharyngeal pouches.

\section{Results and Discussion}

At embryonic (E) day 11.5, Tbx 1 was expressed in the epithelium of the early facial primordia; the frontonasal process in the midline and the medial and lateral nasal processes more peripherally, this expression being confluent with the epithelium at the base of the nasal pits (Fig. 1A). In the early stomatodium, Tbx1 was present throughout the epithelium, but was upregulated in the localised thickenings of presumptive tooth germs (Fig. 1B). More proximally, strong expression existed in the pharyngeal endoderm and pre-muscular masses of the lateral lingual swellings and tuberculum impar of the developing tongue. Interestingly, expression was also present bilaterally in the primordial condensations of Meckel's cartilage, within the first pharyngeal arch (Fig. 1C). In the more proximal regions of the early face, Tbx 1 was expressed in epithelium of the early laryngeal orifice and epiglotic swelling (Fig. 1D). Expression was also strong in ectoderm of the tubotympanic recess and the pharyngeal endoderm, in addition to pharyngeal mesoderm surrounding the internal jugular vein (Fig. 1E). Further proximally, Tbx 1 transcripts were strongly localised to the lateral ectoderm of the otic vesicle (Fig. 1F).

From E12.5-13.5, Tbx 1 was expressed in the epithelium at the
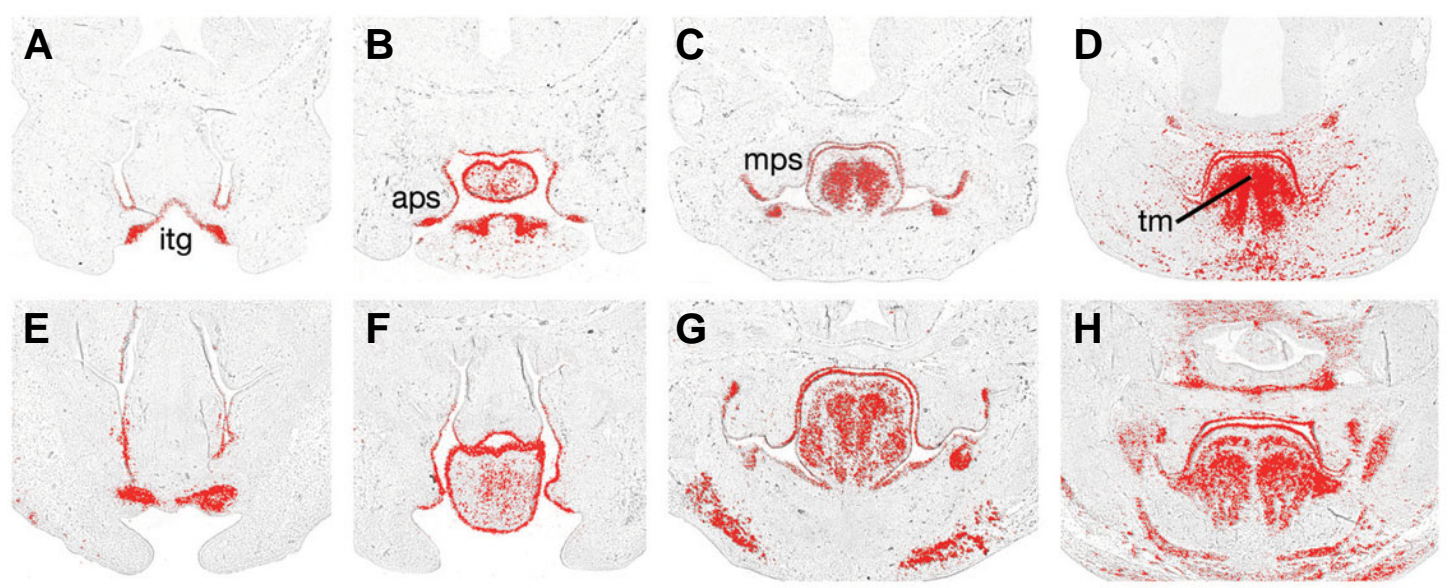

Fig. 2. Tbx 1 expression in the craniofacial region of the developing mouse embryo at E12.5 (A-D) and E13.5 (E-H). Tbx1 is expressed in the epithelial component of the incisor tooth germs $(\mathbf{A}, \mathbf{E})$. In the developing palate, transcripts are expressed throughout the epithelium of the palatine shelves, with intense expression anteriorly $(\mathbf{B}, \mathbf{F})$ and on the buccal sides more proximally $(\mathbf{C}, \mathbf{G})$. In the pharyngeal regions, Tbx1 is expressed

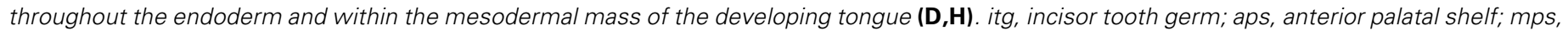
mid palatal shelf; tm, tongue mesoderm. 
floor of the nasal cavities and became restricted to the odontogenic epithelium of the early tooth buds (Fig. 2A, E). In the maxilla, $T b \times 1$ transcripts were present throughout the epithelium of the early palatine processes of the maxilla anteriorly (Fig. 2B, F). These palatine processes lie bilaterally adjacent to the developing tongue and are destined to elevate and fuse in the midline with their counterpart on the opposite side. Tbx 1 demonstrated lowlevel transcription throughout the epithelium of these shelves in the mid-portion of the palate, but was upregulated markedly on the buccal sides (Fig. 2C, G). More proximally, Tbx 1 remained strong in the pharyngeal endoderm and mesoderm, with transcription also present in the epithelium and intrinsic musculature of the developing tongue (Fig. 2D, $\mathrm{H}$ ).

By E14.5 the palatine shelves have elevated above the tongue and are fusing with each other in the midline and with the nasal septum superiorly. Tbx 1 was expressed in the epithelium of the nasal cavity, septum and palatal shelves (Fig. 3A-D); and interestingly, in the mid-epithelial seam of the palate where fusion is mediated (Fig. 3B-D, arrowed). In the tongue, expression continued in the epithelium and within both the intrinsic and extrinsic musculature (Fig. 3A-C), whilst strong expression was maintained in the pharyngeal mesoderm (Fig. 3D).

During the initiation of tooth development at E11.5, Tbx 1 was strongly expressed in the localised thickenings of odontogenic epithelium that form the presumptive tooth germs (see Fig. 1B) and this expression continued in the epithelium of the early tooth bud, being marked particularly on the lingual side (Fig. 4A). At the late bud stage, $T b \times 1$ remained strong in the lingual and basal regions of the invaginating tooth bud (Fig. 4B). The transition from bud to cap stage is marked by complex morphological changes in the tooth germ as the essential crown shape of the tooth is delineated. At the early cap stage, Tbx 1 transcripts were localised to the peripheral and basal regions of the epithelial cap (Fig. 4C). During the late cap stage, differentiation of distinct cell populations within the epithelial component of the tooth germ begins. Within these distinct epithelial cell populations, Tbx 1 was present peripherally in the external and internal enamel epithelia and enamel knot. In contrast, internally within the stellate reticulum of the enamel organ, Tbx 1 transcripts were absent (Fig. 4D). By the early bell stage, Tbx 1 was restricted to the internal enamel epithelium, which is destined to form the ameloblasts responsible for enamel production (Fig. 4E).

Prior to the onset of hair follicle development in the facial region, Tbx 1 expression was absent from the embryonic epidermis, but during initiation, expression upregulated in localised regions of invaginating epithelium that form the early stage 1 epidermal placode (Fig. 4F). During stages 2-3 of hair follicle morphogenesis, as invagination of the epidermis forms the hair germ and then plug, Tbx 1expression remained strong throughout these structures (Fig. 4G). Further ingrowth of the follicular epidermis during stage 4 was accompanied by strong $T b \times 1$ expression in the epidermal component of the early hair follicle (Fig. 4H). At stage 5, differentiation of cellular components within the hair follicle is complete and Tbx 1 expression was restricted to cells of the outer root sheath that surround the future hair shaft and dermal papilla. No transcripts were detectable in the hair matrix or dermal papilla itself, but interestingly $T b \times 1$ was upregulated in mesenchymal cells situated between the developing hair follicles (Fig. 4I). During early growth of the hair follicle,
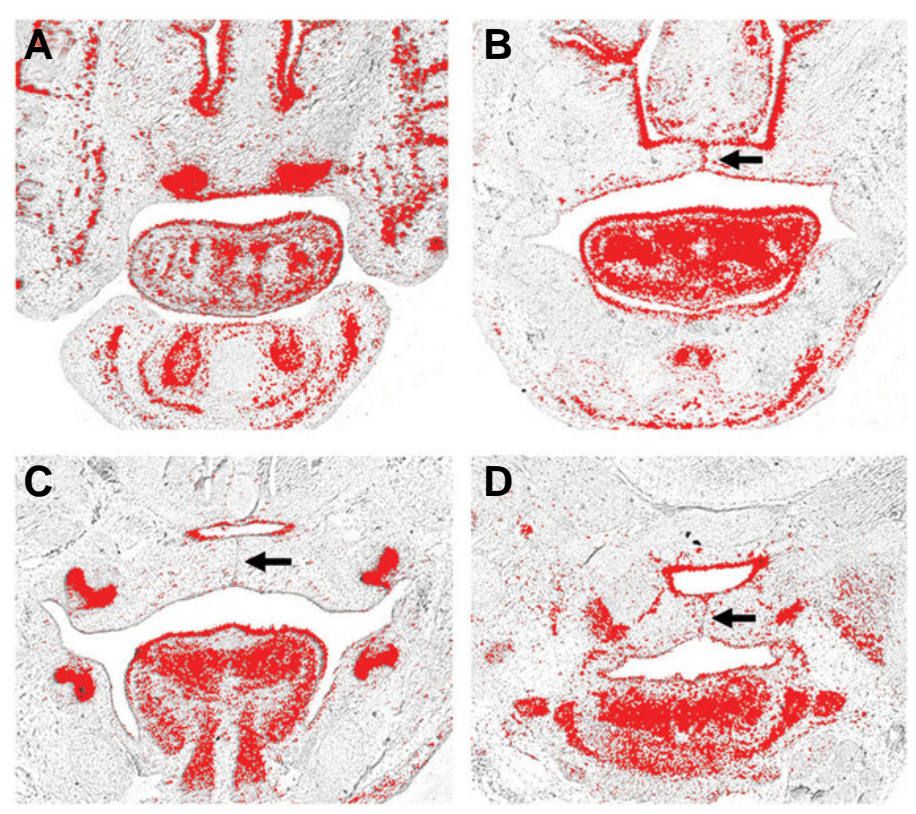

Fig. 3. Tbx1 expression in the craniofacial region of the developing mouse embryo at E14.5 (A-D). Tbx1 is expressed in the incisor and molar tooth germs $(\mathbf{A}, \mathbf{C})$, epithelium of the nasal cavity $(\mathbf{A}, \mathbf{B})$, epithelium of the fused palatal shelves (B-D) including the midpalatal seam (arrowed) and the pharyngeal endoderm and mesoderm (D).

Tbx 1expression continued in the outer root sheath but downregulated in the surrounding mesenchyme (Fig. 4J).

DGS/VCFS subjects have a spectrum of congenital malformations that are thought to arise from anomalies in development of the pharyngeal pouches (Kochilas et al., 2002, Vitelli et al., 2002a). To date, most investigations into the developmental basis of these syndromes have concentrated upon defects within the cardiovascular system (Baldini, 2002). DGS/VCFS are also associated with anomalies in the craniofacial region, principally varying degrees of facial dysmorphology and cleft palate. The aetiology of these disruptions is less well understood, but the expression of $T b \times 1$ is consistent with an important role in mediating some of the complex interactions that govern early development of the facial region and its appendages. A key question is whether Tbx 1 integrates into some of the currently known signalling pathways that regulate facial development.

The epithelium of the early face expresses members of several signalling molecule families, including Bone morphogenetic proteins (Bmp), Fibroblast growth factors (Fgf), Hedgehog, Retinoid and Wnt, which mediate many of the interactions that govern outgrowth, patterning and differentiation of the facial primordia and pharyngeal arches (Francis-West et al., 2003). Genetic links between $T b \times 1$ transcription and signaling from several members of these families have been elucidated in several model organisms. Retinoic acid is important for patterning the pharyngeal arches and fronto-nasal region of the embryonic face and endogenous levels appear to be important for normal regulation of Tbx 1 (Roberts et al., 2005), a finding consistent with DGS-type defects in embryos exposed to increased (Mulder et al., 2000, Mulder et al., 1998) or reduced (Niederreither et al., 2003, Vermot et al., 2003) retinoid signaling. Fgf8 is also important during early morphogenesis and outgrowth of the facial processes and first 
pharyngeal arch (Abzhanov and Tabin, 2004, Firnberg and Neubuser, 2002, Trumpp et al., 1999). In the pharyngeal endoderm and cardiac outflow tract, Fgf8expression overlaps with and

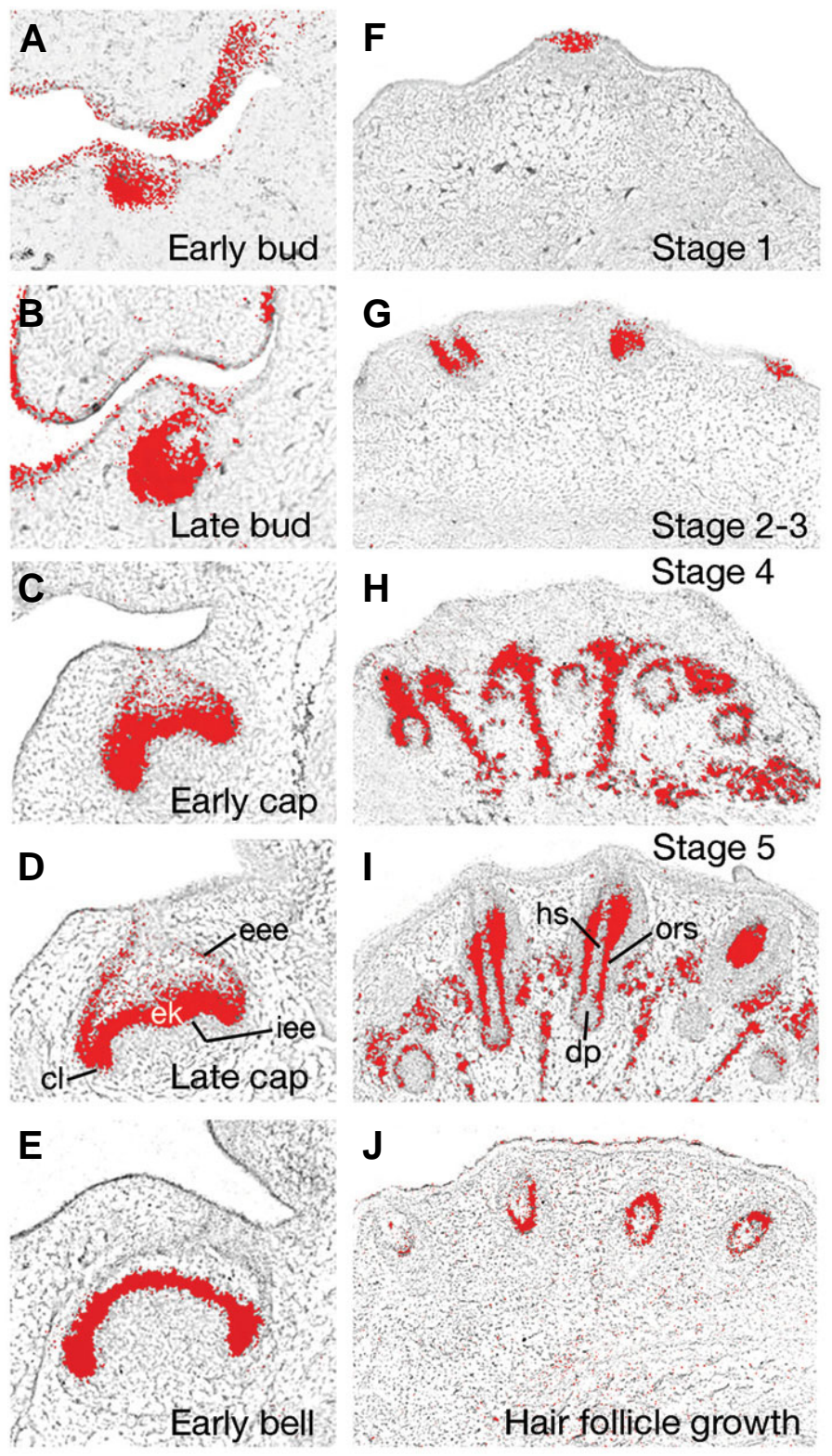

Fig. 4. Tbx1 expression in the developing tooth (A-E) and hair follicle (F-J). Transcripts are present within the epithelial component of the tooth germ at the early (A) and late bud (B) stages. During the early (C) and late cap stages (D) expression is present in the external and internal enamel epithelia, being continuous at the cervical loop and enamel knot. By the early bell stage (E) expression has localised to the internal enamel epithelium. In the developing hair follicle, Tbx1 is expressed in the epithelium of the early stage 1 epidermal placode (F) and hair plug, i.e. stage 2-3 (G). During stages 4 (H) and 5 (I) of hair follicle morphogenesis, Tbx1 progressively localises to the outer root sheath of the epithelial component, with expression in the surrounding mesenchyme. In the early hair follicle (J), Tbx1 is present in the outer root sheath but has downregulated in the surrounding mesenchyme. cl, cervical loop; dp, dermal papilla; ek, enamel knot; hs, hair shaft; eee, external enamel epithelium; iee, internal enamel epithelium; ors, outer root sheath. lies downstream of Tbx1, (Hu et al., 2004, Vitelli et al., 2002b); with reduced Fgfo activity in mice leading to cardiovascular and pharyngeal defects characteristic of DGS/VCFS (Abu-Issa et al., 2002, Frank et al., 2002). The co-expression of Tbx1 with Fgf8 in the facial epithelium of the fronto-nasal process, medial and lateral nasal processes and first pharyngeal arch suggests that in DGS/VCFS subjects, facial dysmorphogenesis may be associated with altered levels of Fgf8 activity in these regions.

Shh signalling is also important for facial development. Shh mutants have disruption in early patterning of the neural plate, resulting in a failure of forebrain cleavage and holoprosencephaly (Chiang et al., 1996). During later stages of facial development, Shh is essential for morphogenesis of the fronto-nasal and maxillary processes; loss of Shh signalling in these region inhibits growth, resulting in hypotelorism and cleft lip/palate, whilst excess signal leads to a mediolateral widening or hypertelorism $\mathrm{Hu}$ and Helms, 1999). Tbx1 expression coincides with that of Shhin the epithelium of these early facial primordia, in addition to several other regions of epithelial-mesenchymal interaction; notably the palatine processes of the maxilla, developing tooth germs and hair follicles.

Tbx 1 expression is dependent upon Shh signalling in certain discreet regions of the craniofacial complex, being downregulated in the mesodermal core and lost in the pharyngeal endoderm of the pharyngeal arch system in Shh-/- mutant mice (Garg et al., 2001). In addition, in vivo evidence exists for the molecular regulation of $T b \times 1$ in these regions via Shh-induced activity of Foxa and c-class transcription factors (Yamagishi et al., 2003). In the anterior palate, a network of genetic interaction regulates Shh transcription within the medial edge epithelium (MEE) via Msx1maintained expression of $B m p 4$ within the underlying mesenchyme and in turn, Shh-induced mesenchymal expression of Bmp2, functioning to induce cell proliferation within the palatal shelves (Zhang etal., 2002). Shhis a downstream target of Fgf10Fgfr2b signalling within this region (Rice et al., 2004) and Fgf10 lies downstream of $\mathrm{Tb} \times 1$ in the embryonic heart field ( $\mathrm{Hu}$ et al., 2004, Xu et al., 2004). The expression of Tbx 1 in the MEE of the anterior palatine shelves and findings that $T b \times 1$-/- mutant mice exhibit cleft palate (Jerome and Papaioannou, 2001, Lindsay et al., 2001, Merscher et al., 2001) provide strong indirect evidence of a role for $T b \times 1$ during these stages of palatogenesis, possibly mediated by Shh signalling.

$T b \times 1$ is also co-expressed with Shh in the epithelial compartment of organs that develop via reciprocal signalling between epithelium and mesenchyme. In the developing tooth germ, Shh appears to be essential for initiation and subsequent morphogenesis (Cobourne et al., 2001, Dassule et al., 2000, Gritli-Linde et al., 2002, Sarkar et al., 2000), whilst in the hair follicle it regulates growth and morphogenesis directly and has an indirect effect upon maturation (Chiang et al., 1999, Karlsson et al., 1999, StJacques et al., 1998). The co-expression of Shh and Tbx 1 in the epithelium of these organs during crucial stages of early development is also suggestive of molecular interaction in these regions. Indeed, mutations in the human $\mathrm{SHH}$ gene can cause maxillary incisor hypodontia (Garavelli etal., 2004, Nanni etal., 2001); Tbx1 -/- mice have defects in the maxillary incisors (Jerome and Papaioannou, 2001) and VCFS has been associated with the presence of a single maxillary incisor (Oberoi and Vargervik, 2005). 
The highly localised expression domains of $T b x 1$ in the facial regions of the early embryo suggest a role in epithelial-mesenchymal interaction during development of the facial prominences and appendages. Existing genetic evidence from other regions of the embryo and the domains of considerable co-expression make it likely that interaction exists with Hedgehog and Fgf family members.

\section{Experimental Procedures}

\section{Animals}

CD-1 mice were time-mated and pregnant females sacrificed with cervical dislocation. Matings were set up such that noon of the day on which vaginal plugs were detected was considered as E0.5. Embryonic heads were collected at different stages (E11.5$\mathrm{E} 15.5)$ and fixed in $4 \%(\mathrm{w} / \mathrm{v})$ paraformaldehyde at $4^{\circ} \mathrm{C}$ overnight. Following this, heads were washed in PBS, dehydrated through a graded series of ethanols, embedded in paraffin wax and sectioned at $7 \mu \mathrm{m}$ in preparation for in situ hybridisation.

\section{In situ hybridisation}

Radioactive section in situhybridisation using ${ }^{35} \mathrm{~S}-U T P$ radiolabelled riboprobes was performed as previously described (Wilkinson, 1992). Tbx1 antisense riboprobes were generated from a mouse cDNA clone, a kind gift of Prof Pete Scambler $(\mathrm{ICH}$, UCL, UK). Both light and dark-field images were photographed using a Zeiss Axioscope microscope and merged using Adobe Photoshop CS.

\section{Acknowledgements}

This work was funded by a European Orthodontic Society Research Fellowship (MTC) and a GKT Dental Institute Studentship (MZ).

\section{References}

ABU-ISSA, R., SMYTH, G., SMOAK, I., YAMAMURA, K. and MEYERS, E.N. (2002). Fgf8 is required for pharyngeal arch and cardiovascular development in the mouse. Development 129: 4613-25.

ABZHANOV, A. and TABIN, C.J. (2004). Shh and fgf8 act synergistically to drive cartilage outgrowth during cranial development. Dev Bio/273: 134-48.

BALDINI, A. (2002). Digeorge syndrome: The use of model organisms to dissect complex genetics. Hum Mol Genet 11: 2363-9.

BALDINI, A. (2005). Dissecting contiguous gene defects: Tbx1. Curr Op Genet Dev 15: 279-284.

CHAPMAN, D.L., GARVEY, N., HANCOCK, S., ALEXIOU, M., AGULNIK, S.I., GIBSON-BROWN, J.J., CEBRA-THOMAS, J., BOLLAG, R.J., SILVER, L.M. and PAPAIOANNOU, V.E. (1996). Expression of the t-box family genes, tbx1tbx5, during early mouse development. Dev Dyn 206: 379-90.

CHIANG, C., LITINGTUNG, Y., LEE, E., YOUNG, K.E., CORDEN, J.L., WESTPHAL, H. and BEACHY, P.A. (1996). Cyclopia and defective axial patterning in mice lacking sonic hedgehog gene function. Nature 383: 407-13.

CHIANG, C., SWAN, R.Z., GRACHTCHOUK, M., BOLINGER, M., LITINGTUNG, Y., ROBERTSON, E.K., COOPER, M.K., GAFFIELD, W., WESTPHAL, H., BEACHY, P.A. et al.,. (1999). Essential role for sonic hedgehog during hair follicle morphogenesis. Dev Bio/205: 1-9.

CHIEFFO, C., GARVEY, N., GONG, W., ROE, B., ZHANG, G., SILVER, L., EMANUEL, B.S. and BUDARF, M.L. (1997). Isolation and characterization of a gene from the digeorge chromosomal region homologous to the mouse tbx1 gene. Genomics 43: 267-77.

COBOURNE, M.T., HARDCASTLE, Z. and SHARPE, P.T. (2001). Sonic hedgehog regulates epithelial proliferation and cell survival in the developing tooth germ. $\checkmark$ Dent Res 80: 1974-9.
DASSULE, H.R., LEWIS, P., BEI, M., MAAS, R. and MCMAHON, A.P. (2000). Sonic hedgehog regulates growth and morphogenesis of the tooth. Development 127 : 4775-4785.

FIRNBERG, N. and NEUBUSER, A. (2002). Fgf signaling regulates expression of tbx2, erm, pea3 and pax3 in the early nasal region. Dev Bio/247: 237-50.

FRANCIS-WEST, P.H., ROBSON, L. and EVANS, D.J.R. (2003). Craniofacial development: The tissue and molecular interactions that control development of the head. Adv Anat Emb Cel/ Bio/169: 1-144.

FRANK, D.U., FOTHERINGHAM, L.K., BREWER, J.A., MUGLIA, L.J., TRISTANIFIROUZI, M., CAPECCHI, M.R. and MOON, A.M. (2002). An fgf8 mouse mutant phenocopies human 22q11 deletion syndrome. Development 129: 4591-603.

GARAVELLI, L., ZANACCA, C., CASELLI, G., BANCHINI, G., DUBOURG, C., DAVID, V., ODENT, S., GURRIERI, F. and NERI, G. (2004). Solitary median maxillary central incisor syndrome: Clinical case with a novel mutation of sonic hedgehog. Am J Med Genet A 127: 93-5.

GARG, V., YAMAGISHI, C., HU, T., KATHIRIYA, I.S., YAMAGISHI, H. and SRIVASTAVA, D. (2001). Tbx1, a digeorge syndrome candidate gene, is regulated by sonic hedgehog during pharyngeal arch development. Dev Biol 235: 62-73.

GRITLI-LINDE, A., BEI, M., MAAS, R., ZHANG, X.M., LINDE, A. and MCMAHON, A.P. (2002). Shh signalling within the dental epithelium is necessary for cell proliferation, growth and polarization. Development 129: 5323-5337.

HERRMANN, B.G., LABEIT, S., POUSTKA, A., KING, T.R. and LEHRACH, H. (1990). Cloning of the $t$ gene required in mesoderm formation in the mouse. Nature 343: 617-22.

HU, D. and HELMS, J.A. (1999). The role of sonic hedgehog in normal and abnormal craniofacial morphogenesis. Development 126: 4873-84.

HU, T., YAMAGISHI, H., MAEDA, J., MCANALLY, J., YAMAGISHI, C. and SRIVASTAVA, D. (2004). Tbx1 regulates fibroblast growth factors in the anterior heart field through a reinforcing autoregulatory loop involving forkhead transcription factors. Development 131: 5491-502.

JEROME, L.A. and PAPAIOANNOU, V.E. (2001). Digeorge syndrome phenotype in mice mutant for the t-box gene, tbx1. Nat Genet 27: 286-91.

KARLSSON, L., BONDJERS, C. and BETSHOLTZ, C. (1999). Roles for pdgf-a and sonic hedgehog in development of mesenchymal components of the hair follicle. Development 126: 2611-21.

KLEWER, S.E., RUNYAN, R.B. and ERICKSON, R.P. (2004). Tbx1 and the digeorge syndrome critical region. Oxford University Press, New York.

KOCHILAS, L., MERSCHER-GOMEZ, S., LU, M.M., POTLURI, V., LIAO, J., KUCHERLAPATI, R., MORROW, B. and EPSTEIN, J.A. (2002). The role of neural crest during cardiac development in a mouse model of digeorge syndrome. Dev Bio/251: 157-66.

KOCHILAS, L.K., POTLURI, V., GITLER, A., BALASUBRAMANIAN, K. and CHIN, A.J. (2003). Cloning and characterization of zebrafish tbx1. Gene ExprPatterns 3: 645-51.

LINDSAY, E.A., VITELLI, F., SU, H., MORISHIMA, M., HUYNH, T., PRAMPARO, T., JURECIC, V., OGUNRINU, G., SUTHERLAND, H.F., SCAMBLER, P.J. et al.,. (2001). Tbx1 haploinsufficieny in the digeorge syndrome region causes aortic arch defects in mice. Nature 410: 97-101.

MERSCHER, S., FUNKE, B., EPSTEIN, J.A., HEYER, J., PUECH, A., LU, M.M., XAVIER, R.J., DEMAY, M.B., RUSSELL, R.G., FACTOR, S. etal.,. (2001). TbX1 is responsible for cardiovascular defects in velo-cardio-facial/digeorge syndrome. Cel/104: 619-29.

MULDER, G.B., MANLEY, N., GRANT, J., SCHMIDT, K., ZENG, W., ECKHOFF, C. and MAGGIO-PRICE, L. (2000). Effects of excess vitamin a on development of cranial neural crest-derived structures: A neonatal and embryologic study. Teratology 62: 214-26.

MULDER, G.B., MANLEY, N. and MAGGIO-PRICE, L. (1998). Retinoic acidinduced thymic abnormalities in the mouse are associated with altered pharyngeal morphology, thymocyte maturation defects and altered expression of hoxa3 and pax1. Teratology 58: 263-75.

NANNI, L., MING, J.E., DU, Y., HALL, R.K., ALDRED, M., BANKIER, A. and MUENKE, M. (2001). Shh mutation is associated with solitary median maxillary central incisor: A study of 13 patients and review of the literature. Am J Med Genet 102: 1-10.

NIEDERREITHER, K., VERMOT, J., LE ROUX, I., SCHUHBAUR, B., CHAMBON, 


\section{M. Zoupa et al.}

P. and DOLLE, P. (2003). The regional pattern of retinoic acid synthesis by raldh2 is essential for the development of posterior pharyngeal arches and the enteric nervous system. Development 130: 2525-34.

OBEROI, S. and VARGERVIK, K. (2005). Velocardiofacial syndrome with a single central incisor. Am J Med Genet 132: 194-197.

RICE, R., SPENCER-DENE, B., CONNOR, E.C., GRITLI-LINDE, A., MCMAHON, A.P., DICKSON, C., THESLEFF, I. and RICE, D.P. (2004). Disruption of fgf10/ fgfr2b-coordinated epithelial-mesenchymal interactions causes cleft palate. $J$ Clin Invest 113: 1692-700.

ROBERTS, C., IVINS, S.M., JAMES, C.T. and SCAMBLER, P.J. (2005). Retinoic acid down-regulates tbx1 expression in vivo and in vitro. Dev Dyn232: 928-38.

SARKAR, L., COBOURNE, M., NAYLOR, S., SMALLEY, M., DALE, T. and SHARPE, P.T. (2000). Wnt/shh interactions regulate ectodermal boundary formation during mammalian tooth development. Proc Nat/ Acad Sci USA 97: 4520-4.

SAUKA-SPENGLER, T., LE MENTEC, C., LEPAGE, M. and MAZAN, S. (2002). Embryonic expression of tbx1, a digeorge syndrome candidate gene, in the lamprey lampetra fluviatilis. Gene Expr Patterns 2: 99-103.

SCAMBLER, P.J. (2000). The 22q11 deletion syndromes. Hum Mol Genet9: 24212426.

ST-JACQUES, B., DASSULE, H.R., KARAVANOVA, I., BOTCHKAREV, V.A., LI, J., DANIELIAN, P.S., MCMAHON, J.A., LEWIS, P.M., PAUS, R. and MCMAHON, A.P. (1998). Sonic hedgehog signaling is essential for hair development. Curr Bio/8: 1058-68.

TRUMPP, A., DEPEW, M.J., RUBENSTEIN, J.L., BISHOP, J.M. and MARTIN, G.R. (1999). Cre-mediated gene inactivation demonstrates that fgf8 is required for cell survival and patterning of the first branchial arch. Genes Dev 13: 3136-48.

VERMOT, J., NIEDERREITHER, K., GARNIER, J.M., CHAMBON, P. and DOLLE, $P$. (2003). Decreased embryonic retinoic acid synthesis results in a digeorge syndrome phenotype in newborn mice. Proc Nat/ Acad Sci USA 100: 1763-8.

VITELLI, F., MORISHIMA, M., TADDEI, I., LINDSAY, E.A. and BALDINI, A. (2002a). Tbx1 mutation causes multiple cardiovascular defects and disrupts neural crest and cranial nerve migratory pathways. Hum Mol Genet 11: 915-22.

VITELLI, F., TADDEI, I., MORISHIMA, M., MEYERS, E.N., LINDSAY, E.A. and BALDINI, A. (2002b). A genetic link between tbx1 and fibroblast growth factor signaling. Development 129: 4605-11.

WILKINSON, D.G. (1992). In situ hybridisation: A practical approach. IRL Press, Oxford. UK.

XU, H., MORISHIMA, M., WYLIE, J.N., SCHWARTZ, R.J., BRUNEAU, B.G., LINDSAY, E.A. and BALDINI, A. (2004). Tbx1 has a dual role in the morphogenesis of the cardiac outflow tract. Development 131: 3217-27.

YAGI, H., FURUTANI, Y., HAMADA, H., SASAKI, T., ASAKAWA, S., MINOSHIMA, S., ICHIDA, F., JOO, K., KIMURA, M., IMAMURA, S. et al., (2003). Role of tbx1 in human del22q11.2 syndrome. Lancet 362: 1366-73.

YAMAGISHI, H., MAEDA, J., HU, T., MCANALLY, J., CONWAY, S.J., KUME, T., MEYERS, E.N., YAMAGISHI, C. and SRIVASTAVA, D. (2003). Tbx1 is regulated by tissue-specific forkhead proteins through a common sonic hedgehogresponsive enhancer. Genes Dev 17: 269-81.

ZHANG, Z., SONG, Y., ZHAO, X., ZHANG, X., FERMIN, C. and CHEN, Y. (2002) Rescue of cleft palate in msx1-deficient mice by transgenic bmp4 reveals a network of bmp and shh signaling in the regulation of mammalian palatogenesis. Development 129: 4135-46.

Received: October 2005 Reviewed by Referees: November 2005

Modified by Authors and Accepted for Publication: December 2005 